\title{
Diabetic macular edema: posterior subtenons versus intravitreal injection of steroids
}

\author{
Ashraf Mohammed Gad Elkareem \\ Ophthalmology department, Faculty of medicine, Al-Azhar University, Asyut Branch, Egypt. \\ Corresponding author: Ashraf Mohammed Gad Elkareem, Email: silicon2030@gmail.com, Tel: +2 01060293796
}

\begin{abstract}
Background: Diabetic retinopathy (DR) with diabetic macular edema (DME) is one of the most common complications of diabetes and can lead to visual loss in young individuals.

Purpose: to evaluate the efficacy of posterior subtenon versus intravitreal triamcinolone injection for treatment of diffuse diabetic macular edema.

Patients and methods: seventy six eyes of 64 patients having diffuse diabetic macular edema were included and divided into two groups; Intravitreal triamcinolon acetonide group (IVTA group) included 40 eyes of 30 diabetic individuals, injected with $4 \mathrm{mg}(0.1 \mathrm{ml})$ IVTA. Posterior subtenon triamcinolon acetonide group (STTA group) consists of 36 eyes of 34 diabetic persons injected with $40 \mathrm{mg}(1 \mathrm{ml})$ in the posterior subtenon space.
\end{abstract}

The central subfield macular thickness (CMT) measured with optical coherence tomography (OCT) before injection, 3 and 6 months post-injection was evaluated. Visual acuity as Log MAR, intraocular pressure (IOP) and any complications associated with both techniques ware assessed.

Results: the baseline log MAR VA was significantly improved in both groups at one, three, and six months post-injection .The IVTA and STTA groups had significant reduction in CMT three and six months after steroid injection. The mean IOP was $16.6 \pm 1.3 \mathrm{mmHg}$ and $15.4 \pm 1.1 \mathrm{mmHg}$ at the end of follow up in IVTA and STTA groups respectively.

Conclusion: both intavitreal and subtenons routes of steroid injection are good alternatives for the treatment of diabetic macular edema, but the intravitreal route has a more pronounced effect while the subtenons route is safer.

Keywords: diabetes mellitus; diabetic macular edema; diabetic retinopathy, posterior subtenon.

\section{Introduction}

The World Health Organization (1) and International Diabetes Fedration ${ }^{(2)}$ reported that more than 180 million persons all over the world have diabetes, and this number is going to increase to epidemic percentage within the next 2 decades, 12.1 million of them are in Africa.

Diabetic retinopathy (DR) with diabetic macular edema (DME), one of the most frequent adverse effects of diabetes, stills a big public health problem with significant perdition on the socioeconomic state. It affects about $50 \%$ of diabetic persons and is the leading cause of visual loss in working-age individuals ${ }^{(1)}$.
As severity of DR increases the incidence of macular edema increases as well; approximately $3 \%, 38 \%$, and $71 \%$ of patients with mild nonproliferative diabetic retinopathy (NPDR), moderate to severe NPDR and, proliferative diabetic retinopathy (PDR) have macular edema respectively ${ }^{(3)}$.

The prevalence of diabetic macular edema is directly related to the duration of the diabetes. It is $0 \%$ at 5 years and $29 \%$ at 20 years or more in type I diabetes; however it is $3 \%$ at 5 years and $28 \%$ at 20 years in adult onset diabetes ${ }^{(4)}$. 
One of the mechanisms for the development of diabetic macular edema is the increased retinal vascular leakage secondary to breakdown of the inner blood retinal barrier mediated in part by the vascular endothelial growth factor (VEGF) ${ }^{(5,6)}$.

Laser photocoagulation is the corner stone in macular edema treatment. Although it reduces the risk of vision loss by $50 \%$ or more as reported by the ETDRS ${ }^{(7)}, 40 \%$ of eyes with centrally involved macular edema at baseline still had foveal edema post-laser treatment and it also fails to improve the visual acuity. These results encouraged ophthalmologists to search for other lines of treatment ${ }^{(8,9)}$.

Although the availability of multiple therapeutic medications for treatment of DME, a greater percentage of patients with DME still have some residual edema after multiple intravitreal injections of anti-vascular endothelial growth factor (VEGF) drugs alone ${ }^{(10)}$. Also the economic factor associated with the need for multiple anti VEGF injections is a big issue adding to the deterioration of the macular edema in a large number of patients. These patients are at high risk to loss their vision (11).

Intravitreal injection of corticosteroids (triamcinolone acetonide), constitutes one of the alternatives for the management of diabetic macular edema. The rationale behind steroid use for treatment of diabetic macular edema is that delivery of enough does of the drug into the vitreous cavity will suppress the up regulation of VEGF by the proinflammatory mediators like platelet-derived growth factor and platelet-growth factor, thus improves macular edema ${ }^{(12)}$. Also taking into consideration the obvious role of inflammation in the pathogenesis of DME, corticosteroids have been used for its treatment and it can be given either intravitreal or through the posterior subtenon route ${ }^{(12)}$.

\section{Aim of the study:}

It is to evaluate the effectiveness of intravitreal versus posterior subtenon steroid in the treatment of diabetic macular edema.

\section{Patients and Methods}

It is a randomized prospective comparative study carried out between December 2016 and
September 2017 and recruited seventy-six eyes (76) of diabetic persons having DME according to the ETDRS criteria. The study was carried out in the ophthalmology department, Al-Azhar University Hospital, Asyut.The study was done after the approval of the research and Ethical Committee, School of Medical Sciences, Al-Azhar University, Egypt.

These patients were divided into two groups; Intravitreal triamcinolon group (IVTA group) included 40 eyes of 30 diabetic patients, 19 males and 11 females, 26 patients had type 2 DM while four patients had type $1 \mathrm{DM}$ and they injected with $4 \mathrm{mg}(0.1 \mathrm{ml})$ IVTA .

Posterior subtenon triamcinolon group (STTA group) consists of 36 eyes of 34 diabetic patients, 24 males and ten females, 28 patients had type 2 DM while six patients had type $1 \mathrm{DM}$ and they injected with $40 \mathrm{mg}(1 \mathrm{ml})$ in the posterior subtenon space.

All Included patients had clinically significant macular edema as defined with the ETDRS and a central macular thickness of $\geq 400$ microns by the Optical Coherence Tomography (OCT).

Excluded from these study patients with macular edema due to other causes than diabetes, previous vitrectomy, laser treatment of the macula, intravitreal or subtenon injection of steroid within the last 2 months, patients with cataract and glaucoma are also excluded from the study.

All patients had complete ophthalmic examination including BCVA measured in Decimal chart and converted into Log MAR values at baseline, one, three, and six months of follow up. Anterior segment examination by the slit lamp, fundus examination with the indirect ophthalmoscope and +90D lens, IOP measurement by the applanation tonometry was done for all patients in each visit.

Optical coherence tomography (Time Domain OCT) was done at baseline, 3 , and 6 months postinjection.

\section{Procedure:}

Informed consent was taken from each patient. The injections was done in the operative theater under complete sterile condition. 
Topical anesthesia [Benoxinate $0.4 \%$ eye drop] was applied to the ocular surface followed by $5 \%$ povidone iodine drops in the conjunctival sac. Before injection, the conjunctiva, lids, and lashes were disinfected with $10 \%$ povidone iodine.

TA (Kenacort-A, Bristol-Myers Squibb) was injected slowly with a 27-gauge needle $\quad[4.0 \mathrm{~mm}$ inferotemporal to the limbus in phakic eyes] at a dose of $4 \mathrm{mg}(0.1 \mathrm{ml})$ into the mid-vitreous cavity in the IVTA group patients. Paracentesis was done in selected cases in order to minimize the increase of IOP. We used the indirect ophthalmoscopy to ensure proper intravitreal delivery of the drug and to visualize the optic nerve head perfusion.

Triamcinolon Acetonid of $40 \mathrm{mg}(1 \mathrm{ml})$ were injected $8 \mathrm{~mm}$ from the infrotemporal limbus into the posterior subtenon space using a curved blunt metallic subtenon injection cannula having an arc length of $28 \mathrm{~mm}$ in the STTA group patients. (NAGATA Subtenon injection cannula, 24 gauge/0.6mm. Geuder - Heidelberg, Germany).

A topical antibiotic therapy (Moxifloxacin) was applied 4 times for 7 days after the injection with antiglaucoma treatment in cases with increase of IOP.

Patients were scheduled for follow up at 2nd day to evaluate serious adverse effect like endophthalmitis and IOP elevation. Then at 1st week, 3rd week, 1 month postoperatively then monthly till 6th month after treatment. Significant elevation of the IOP was defined as an increase of more than $5 \mathrm{mmHg}$ from the baseline reading. Significant progression of cataract was monitored and detected by lens opacification classification system III (LOCS).

\section{Statistical analysis:}

Categorical variables were described by number and percent $(\mathrm{N}, \%)$ and continuous variables were described by mean and standard deviation (Mean, SD). Chi-square test used to compare between categorical variables and t-test used to compare between continuous variables. A two-tailed $\mathrm{p}<0.05$ was considered statistically significant. All analyses were performed with the SPSS 20.0 software.

\section{$\underline{\text { Results }}$}

The demographic data of the patients enrolled in both groups are shown in table 1.

All of these patients had ME, DME was present in both eyes in $33.3 \%$ (10/30), 5.9\% (2/34) and in one eye only in $66.7 \%(20 / 30)$, and $94.1 \%(32 / 34)$ in IVTA and STTA groups respectively.

The mean baseline Log MAR and CMT was $0.8 \pm 0.11,0.7 \pm 0.15,495.3 \pm 110.5 \mathrm{um}$, and 465.7 \pm 93.4 um in IVTA group and STTA group respectively.

Table 1: Demographic date of patients in the two studied groups.

\begin{tabular}{|l|l|l|}
\hline Variable & IVTA & STTA \\
\hline No of patients & 30 & 34 \\
\hline No of eyes & 40 & 36 \\
\hline Age & $60.33 \pm 12.51 Y s$ & $61.55 \pm 10.91 \mathrm{Ys}$ \\
\hline Male/Female & $19 / 11$ & $24 / 10$ \\
\hline Type I/Type II DM & $4 / 26$ & $6 / 28$ \\
\hline Baseline Log MAR & $0.8 \pm 0.11$ & $0.7 \pm 0.15$ \\
\hline Baseline CMT & $495.3 \pm 110.5 \mathrm{um}$ & $465.7 \pm 93.4 \mathrm{um}$ \\
\hline
\end{tabular}

\section{A- Changes in Visual acuity:}

- $\quad$ The visual acuity measured as Log MAR (Mean \pm SD) was $0.5 \pm 0.1 ; \mathrm{p}<0.001,0.5 \pm 0.25 ; \mathrm{p}<$ 0.006 , and $0.7 \pm 0.85 ; \mathrm{p}<0.446$ at 1,3 , and 6 months in IVTA group respectively, the visual acuity significantly improved in this group when compared to baseline visual acuity with an average 
improvement of about 3 lines in the first three months post-injection but it worsen again later on.

- $\quad$ The Log MAR visual acuity was $0.5 \pm 0.28$; $\mathrm{p}<0.0013,0.4 \pm 0.47 ; \mathrm{p}<0.0011$, and $0.4 \pm 0.65 ; \mathrm{p}<$ 0.0014 at 1,3 , and 6 months in STTA group respectively as shown in table 2 . The visual acuity significantly improved in this group also when compared to baseline visual acuity with an average improvement of about 2 lines as shown in chart 1.
- $\quad$ The visual acuity significantly improved in both groups at one and three months post-injection without significant difference between them (Pvalue of $0.6231,0.2840)$ but there was a statistically significant difference between both groups at six months after injection $\mathrm{p}<0.0021$. Patients received IVTA showed significant deterioration of visual acuity however patients treated with STTA maintained visual acuity improvement all over the follow up period.

Table 2: Changes of Log MAR visual acuity and the central macular thickness (CMT) in both groups over the follow up period.

\begin{tabular}{|l|l|l|l|l|l|l|}
\hline & \multicolumn{3}{|c|}{ IVTA } & \multicolumn{3}{c|}{ STTA } \\
\hline & Baseline & 3 months & 6 months & Baseline & 3 months & 6 months \\
\hline $\begin{array}{l}\text { Log MAR } \\
\text { VA }\end{array}$ & $0.8 \pm 0.11$ & $0.5 \pm 0.25$ & $0.7 \pm 0.85$ & $0.7 \pm 0.15$ & $0.4 \pm 0.47$ & $0.4 \pm 0.65$ \\
\hline P-value & & 0.006 & 0.44 & & 0.0011 & 0.0014 \\
\hline CMT & $495.3 \pm 110.5$ um & $250.5 \pm 90 \mathrm{um}$ & $305.6 \pm 132.6 \mathrm{um}$ & $465.7 \pm 93.4 \mathrm{um}$ & $205.2 \pm 68.4 \mathrm{um}$ & $255.9 \pm 100.1 \mathrm{um}$ \\
\hline P-value & & 0.004 & 0.023 & & 0.007 & 0.018 \\
\hline
\end{tabular}

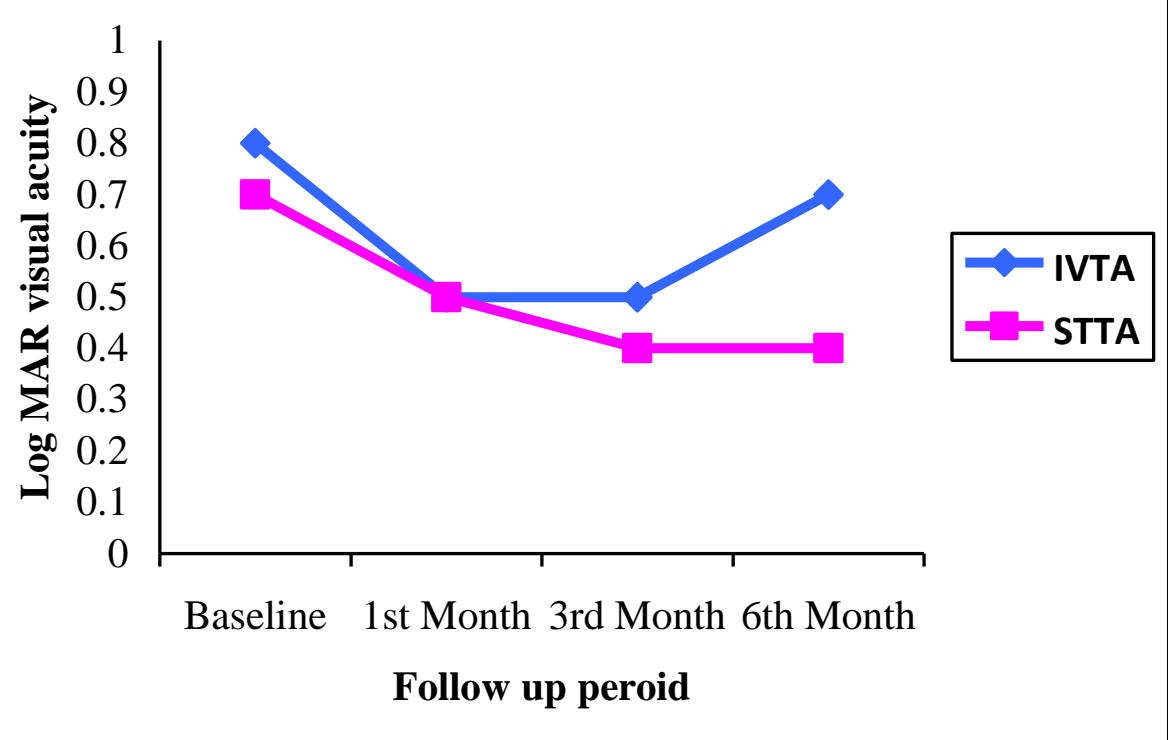

Chart 1: Chart comparing the visual acuity of the two groups over the follow up period.

\section{B- Changes in the central Macular Thickness (CMT):}

The mean CMT (Mean \pm SD) was $495.3 \pm 110.5$ um, 250.5 \pm 90 um, and $305.6 \pm 132.6 u m$ in IVTA group at baseline, 3 , and 6 months respectively. It was $465.7 \pm 93.4 \mathrm{um}, \quad 205.2 \pm 68.4 \mathrm{um}$, and $255.9 \pm 100.1 \mathrm{um}$ in STTA group at baseline, 3, and 6 months respectively as shown in table 2 and chart 2 . 
Both groups had improvement in the central macular thickness in the first three months postinjection (250.5 $\pm 90 \mathrm{um}, \mathrm{p} \quad 0.004$ and 205.2 \pm 68.4 um, p 0.007 in the IVTA and STTA groups respectively) when compared to baseline CMT. However there was a significant difference between both groups at the end of 6 months follow up, where the reduction in the CMT was about 190 $\mathrm{um}(38 \%)$, and $210 \mathrm{um}(45 \%)$ in IVTA and STTA groups respectively as shown in chart 2 and Figure $1 \& 2$. We found that the difference between the two groups was statistically significant and the $\mathrm{P}$ value was 0.0015 .

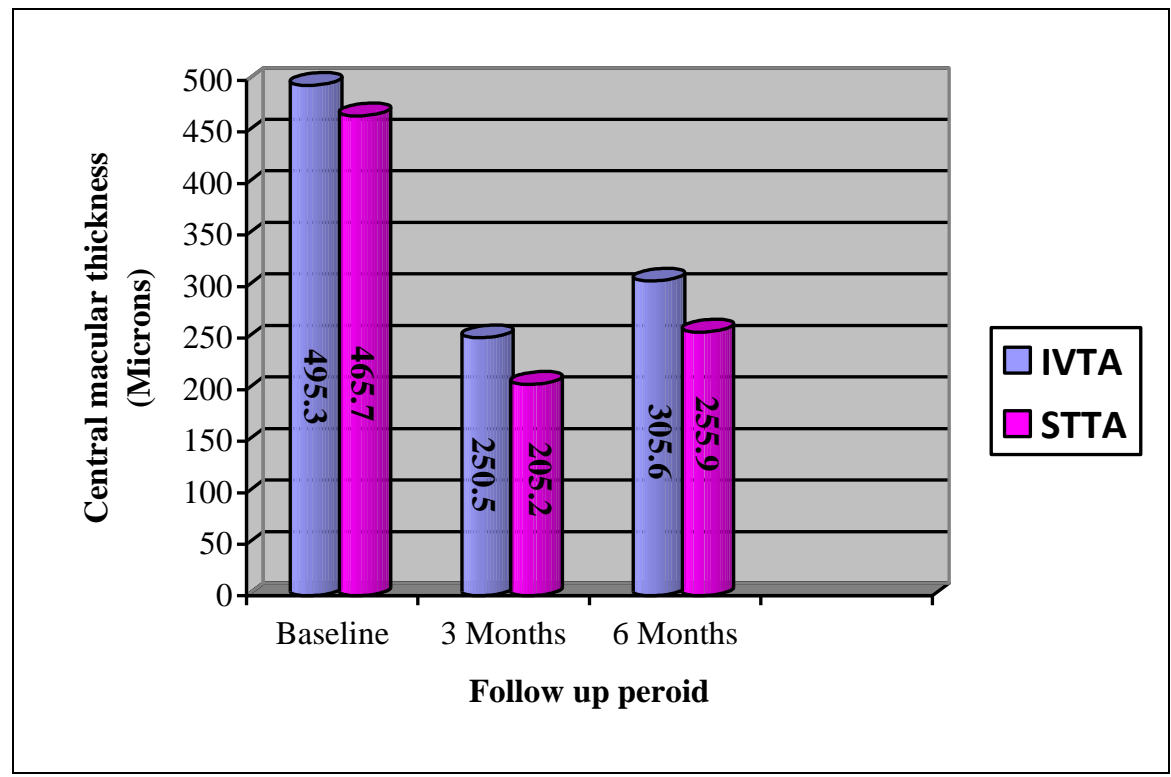

Chart 2: Changes in the Central macular thickness over the follow up period in both groups.
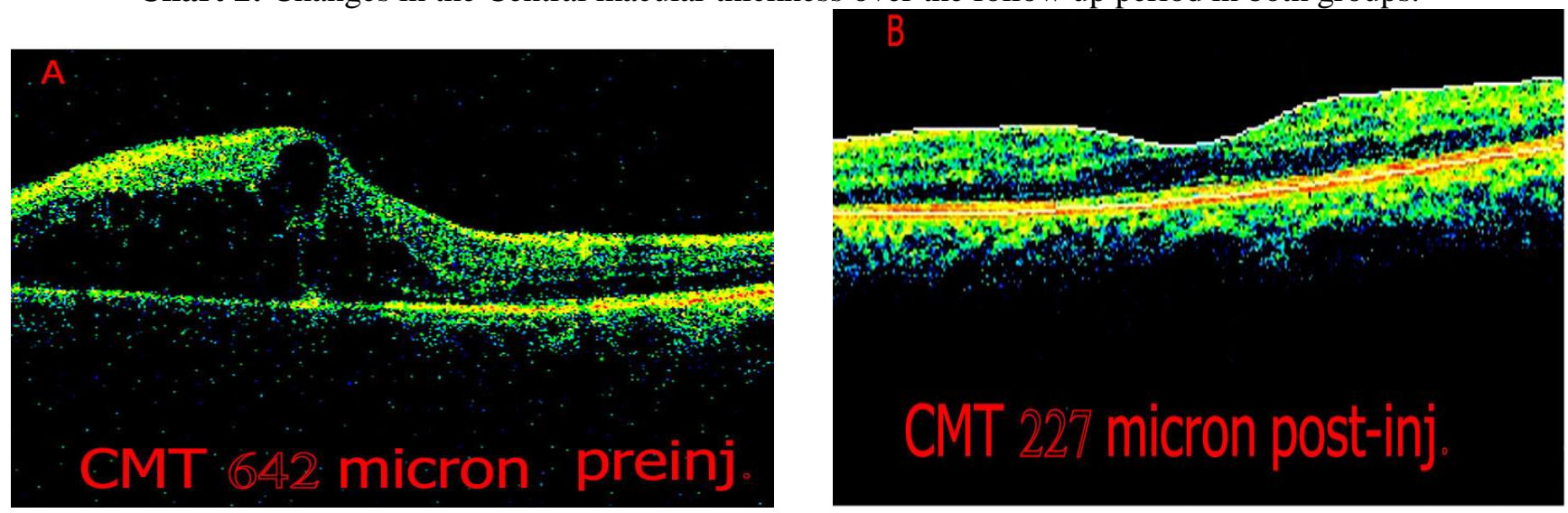

Figure 1: An OCT images showing; (A)diabetic macular edema with a central macular thickness of $642 \mu \mathrm{m}$ pre-injection with steroid and (B) improvement of the macular edema to $227 \mu \mathrm{m}$ three months post-injection with intravitreal steroid. 

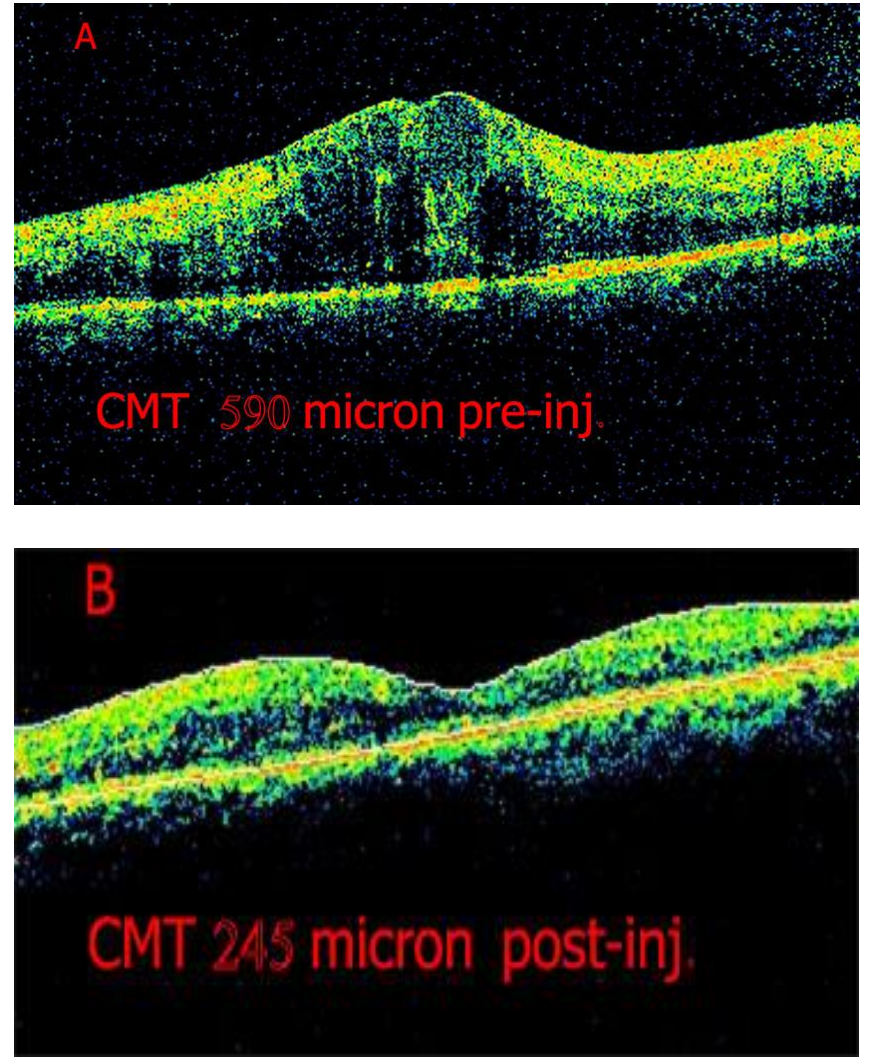

Figure 2: An OCT images showing; (A)diabetic macular edema with a central macular thickness of $590 \mu \mathrm{m}$ pre-injection with steroid and (B) improvement of the macular edema to $245 \mu \mathrm{m}$ three months post-injection with subtenons steroid.

\section{$\underline{\text { C- Intra ocular pressure: }}$}

- The mean IOP was $15.3 \pm 1.1 \mathrm{mmHg}$, $21 \pm 4.9 \mathrm{mmHg}, 16.8 \pm 1.5 \mathrm{mmHg}$, and $16.6 \pm 1.3$ $\mathrm{mmHg}$ at baseline, one, three, and six months respectively in the IVTA group. But it was $15.1 \pm 1.7 \mathrm{mmHg}, \quad 17.5 \pm 1.9 \mathrm{mmHg}, \quad 16.1 \pm 1.5$ $\mathrm{mmHg}$ and $15.4 \pm 1.1 \mathrm{mmHg}$ at baseline, one, three, and six months respectively in the STTA group (table 3).

Table 3: changes of IOP in both groups over the follow up period.

\begin{tabular}{|l|l|l|l|}
\hline IOP/ Group & IVTA & STTA & P-value \\
\hline Baseline & $15.3 \pm 1.1 \mathrm{mmHg}$ & $15.1 \pm 1.7 \mathrm{mmHg}$ & 0.5 \\
\hline One month & $21 \pm 4.9 \mathrm{mmHg}$ & $17.5 \pm 1.9 \mathrm{mmHg}$ & 0.0130 \\
\hline Three months & $16.8 \pm 1.5 \mathrm{mmHg}$ & $16.1 \pm 1.5 \mathrm{mmHg}$ & 0.3 \\
\hline Six months & $16.6 \pm 1.3 \mathrm{mmHg}$ & $15.4 \pm 1.1 \mathrm{mmHg}$ & 0.1 \\
\hline
\end{tabular}

The IOP in the IVTA group increases about $5 \mathrm{mmHg}$ in the first 2 months from the baseline level and returned into its baseline level after three months without the need for any antiglaucoma medication or surgery except in two patients where the IOP increased to about $30 \mathrm{mmHg}$. It is controlled with a combination of beta Blocker with carbonic anhydrase inhibitor eye drops and returned to its baseline level three months after treatment and they did not require continuation of treatment.

As regard the IOP in the STTA group it increased slightly in the first month post-injection and then remains almost unchanged $1.0-2.0 \mathrm{mmHg}$ from the baseline level throughout the follow up period. The difference in the two groups was statistically significant $(\mathrm{p}=0.0130)$. 


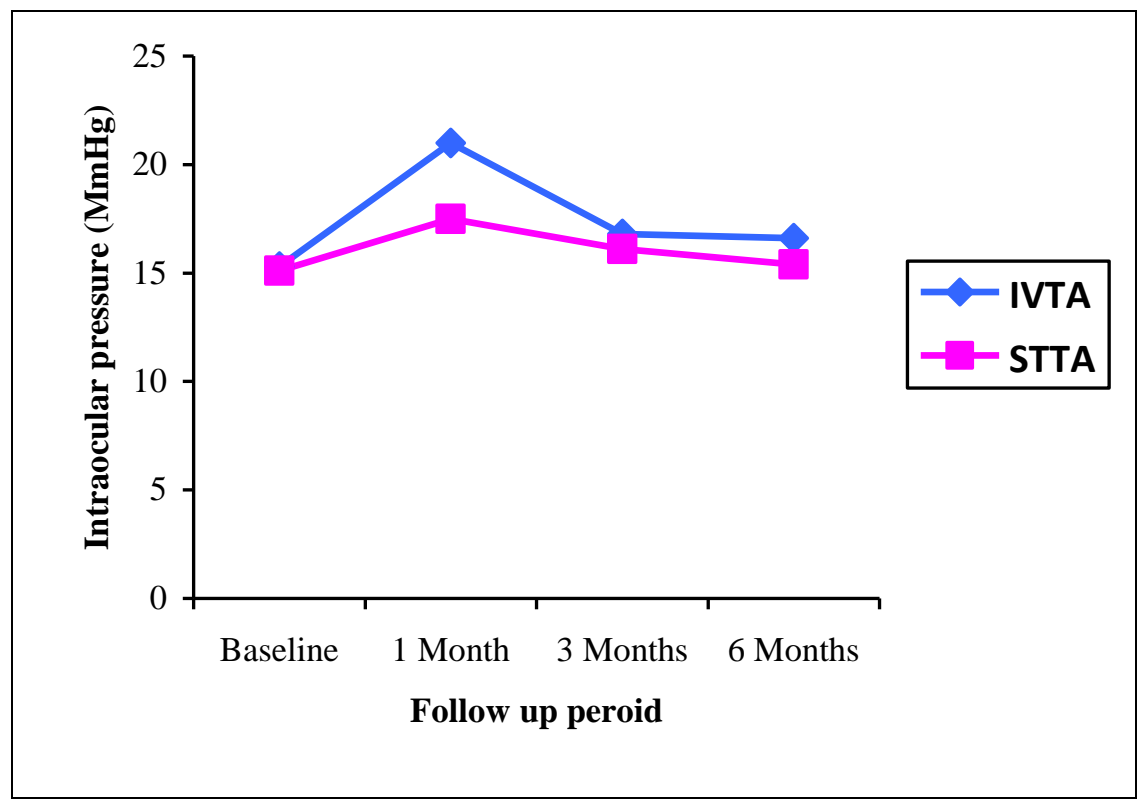

Chart 3: Changes in intra ocular pressure in both groups over the follow up period.

\section{Complications:}

- Recurrence of macular edema was responsible for deterioration of the visual acuity in two patients one in each studied group two months post-injection.

- $\quad$ Posterior subcapsular cataract developed in three eyes five months post injection in the IVTA group.

\section{Discussion}

Chronic macular edema is the main cause of visual deterioration in diabetic patients. The pathogenesis of diabetic retinopathy and macular edema is linked to damage of the outer and inner blood retinal barriers resulting in fluid leakage into the retinal tissues, it is also associated with chronic inflammation like pathology ${ }^{(13,14)}$. This is evidenced by elevated levels of prostacyclin (15), vascular endothelial growth factor (VEGF), macrophagic cellular component and increased vascular leakage in diabetic persons ${ }^{(16)}$.

Corticosteroids administration will suppress the first step of arachidonic acid cascade, and support the blood-retinal barriers ${ }^{(17,18)}$. Intravitreal steroid injections carries some hazards as endophthalmitis, vitreous hemorrhages, retinal detachment, IOP elevation, and cataract formation (19).
Posterior subtenons approach is another pathway of steroid injection for treatment of macular edema and uveal inflammation. This approach is minimally invasive and act as a reservoir delivering sufficient dose of TA to the macular area over a longer time ${ }^{(19,20)}$.

In current study, the studied groups achieved a significant improvement in both visual acuity and the central macular thickness. These results are in agreement with studies of Choi et al. ${ }^{(21)}$, Elfassi $\boldsymbol{e t}$ $a l^{(22)}$, and Lotfy ${ }^{(23)}$.

The visual acuity improvement in our study is in agreement with the studies that found both IVTA and STTA can improve the VA of patients, up to the fact that STTA may improve VA as well as IVTA. The explanation for this results however is not clear ${ }^{(24,25,26)}$.

Ozdek $\boldsymbol{e t} \boldsymbol{a l}$. and Many other studies (27, 28, 29, 30) compared the IVTA and STTA results. They reported that both STTA and IVTA significantly decreased the retinal edema and improves the visual acuity, although the effects were more pronounced in the IVTA group. The STTA route is a safe and effective one for treatment of DME with a more stable and long duration of the action

The longer duration of action and hence the stability of the results in the subtenon than the intravitreal group could be attributed to that the 
subtenon space may act a reservoir for the steroid delivering a sufficient dose into the vitreous body through the sclera over a longer time. The Triamcinolone Acetonid is eliminated from the vitreous cavity in about one and half months after its intravitreal injection, that is why the effects of intravitreal steroids last only for about three months ${ }^{(31)}$. Bakri and Kaiser ${ }^{(25)}$ stated that STTA was effective for DME that was not responding to laser photocoagulation .

Our results are in contrary to the results of Ibraheem et $\boldsymbol{a l} .{ }^{(32)}$ they stated that the action and the results of the STTA only lasts for one month and it can be considered for as a short term treatment for DME.

Reflux of the TA was noted intra operatively in one patient in the STTA group. This reflux caused a decrease in its therapeutic effect and this patient has no improvement in its CMT. The pharmacokinetics of STTA is that TA diffuses through the sclera to reach the retina, and the effect of STTA is dose dependent. Although the amount of STTA used in this study was $40 \mathrm{mg}$, when drug reflux occurred the actual amount of TA was less than the effective dose ${ }^{(33,19)}$.

The difference in mean IOP at 1 month was significant $(\mathrm{P}=0.0130)$ due to the appearance of secondary glaucoma in the IVTA group, however when it was controlled by medications, the difference in IOP rise become insignificant between the 2 groups with $\mathrm{P}=0.3521$ at 3 months and $\mathrm{P}=0.1205$ at 6 months. However, at all follow up visits the IVTA group showed a higher mean IOP than the STTA group. Again this is in agreement with the results of other studies ${ }^{(21,24,34)}$.

The STTA is minimally invasive than the intravitreal one. IOP is not elevated by subtenons steroid injection except in steroid responders. However Cataract progression, central retinal vein occlusion, globe perforation and central retinal artery occlusion were found to be a complication of $\operatorname{STTA}^{(24)}$.

Other complications described are blepharoptosis, atrophy of the orbital fat, squint, and conjunctival damage ${ }^{(24,34)}$.

\section{Conclusion:}

Intavitreal and subtenons routes of steroid injection are good alternatives for treatment of diabetic macular edema. However the intravitreal route has a more pronounced and short effect while the subtenons route is safer and has longer effect.

\section{Recommendation:}

Further studies with a larger number of patients are needed for more evaluation of the effectiveness of the posterior subtenon approach.

\section{REFERENCES}

1- World Health Organization(2006): Recommendations in Prevention of Blindness from Diabetes Mellitus. Report of a WHO consultation, in Geneva, Geneva, Switzerland.

2- International Diabetes Federation (2009). Diabetic retinopathy. Diabetes Atlas, 4th ed., Brussels.

3- Bresnick GH (1986): Diabetic macular edema: a review. Ophthalmology, 93: 989-97.

4- Klein R, Klein BE, Moss SE, Davis MD(1984): The Wisconsin epidemiological study of diabetic retinopathy. IV. Diabetic macular edema. Ophthalmology, 91: 1464-74.

5- Aiello LP, Gardner TW, King GL, Blankenship G, Cavallerano JD, Ferris FL et al. (1998): Diabetic retinopathy. Technical review. Diabetes Care, 21: 143-156.

6- Aiello LP, Bursell SE, Clermont A, Duh E, Ishii H, Takagi C et al. (1997): Vascular endothelial growth factor-induced retinal permeability is mediated by protein kinase $C$ in vivo and suppressed by an orally effective $\beta$ isoform-selective inhibitor. Diabetes,46:1473-80.

\section{7- $\quad$ Early Treatment Diabetic Retinopathy} Study Research Group (1991): Early photocoagulation for diabetic retinopathy: ETDRS report number 9. Ophthalmology, 98:766-85.

8- Lewis H, Abrams G, Blumenkranz M, Campo R (1992): Vitrectomy for diabetic macular traction and edema associated with posterior hyaloidal traction. Ophthalmology,753-59.

9- Harbour J, Smiddy W, Flynn HJ, 
Rubsamen P (1996): Vitrectomy for diabetic macular edema associated with a thickened and taut posterior hyaloid membrane. Am J Ophthalmol,121:405-13.

10- Bressler SB, Ayala AR, Bressler NM, Melia M, Qin H, Ferris FL, et al. (2016): Persistent macular thickening after ranibizumab treatment for diabetic macular edema with vision impairment. JAMA Ophthalmol.,134:278-85.

11- Ulrich JN(2017): Pars Plana Vitrectomy with Internal Limiting Membrane Peeling for Nontractional Diabetic Macular Edema. The Open Ophthalmology Journal, 11: 5-10

12- Nauck M, Roth M, Tamm M, Eickelberg O, Wieland H, Stulz P et al .(1997): Induction of vascular endothelial growth factor by platelet-activating factor and platelet-derived growth factor is down regulated by corticosteroids. Am J Resp Cell Mol Biol. , 16:398-406.

13- Sander B, Larsen M, Moldow B, LundAndersen H (2001): Diabetic macular edema: passive and active transport of fluorescein through the blood-retina barrier. Invest Ophthalmol Vis Sci., 42:433-438.

14- Kent D, Vinores SA, Campochiaro PA (2000): Macular edema: the role of soluble mediators. Br J Ophthalmol., 84:542-545.

15- Hata Y, Clermont A, Yamauchi T (2000): Retinal expression: regulation. and functional bioactivity of prostacyclin-stimulating factor. J Clin Invest., 106:541-550.

16- Takagi H, Otani A, Kiryu J, Ogura Y (1999): New surgical approach for removing foveal hard exudates in diabetic macular edema. Ophthalmology, 106:249-256.

17- Wilson CA, Berkowitz BA, Sato Y (1992): Treatment with intravitreal steroid reduces bloodretinal barrier breakdown due to retinal photocoagulation. Arch Ophthalmol., 110:11551159.

18- Martidis A, Duker JS, Greenberg PB (2002): Intravitreal triamcinolone for refractory diabetic macular edema. Ophthalmology, 109:920-927.
19- Thomas ER, Wang J, Ege E, Madsen R,
Hainsworth
DP Triamcinolone Acetonide concentration after subtenon injection. Am J Ophthalmol., 142: 860861.

20- Helm CJ, Holland GN (1995): The effects of posterior subtenon injection of triamcinolone actetonide in patients with intermediate uveitis. Am J Ophthalmol., 120:55-64.

21- Choi YJ, Oh IK, Oh JR, Huh K (2006): Intravitreal versus posterior subtenon injection of triamcinolone acetonide for diabetic macular edema. Korean J Ophthalmol., 20: 205-9.

22- Elfassi SA, Hassanein DH, Riad RF, and Hamza HS (2017): Intravitreal versus posterior subtenon injection of triamcinolone acetonide in treatment of diabetic macular edema. Egypt retina Journal, 4:54-60.

23- Lotfy A (2016): Subtenon Triamcinolone Acetonide versus Intravitreal Triamcinolone Acetonide for the Treatment of Diabetic Cystoid Macular Edema. J Clin Exp Ophthalmol.,7: 59093.

24- Cellini M, Pazzaglia A, Zamparini E, Leonetti P, Campos EC (2008): Intravitreal vs. subtenon triamcinolone acetonide for the treatment of diabetic cystoid macular edema. BMC Ophthalmol., 8: 5-11.

25- Bakri SJ and Kaiser PK (2005): Posterior subtenon triamcinolone acetonide for refractory diabetic macular edema. Am J Ophthalmol., 139: $290-4$.

26- Qi HP, Bi S, Wei SQ, Cui H, Zhao JB (2012): Intravitreal versus subtenon triamcinolone acetonide injection for diabetic macular edema: A systematic review and meta-analysis. Curr Eye Res., 37:1136-47.

27- Özdek S, Bahçeci UA, Gürelik G, Hasanreisoğlu B (2006): Posterior subtenon and intravitreal triamcinolone acetonide for diabetic macular edema. J Diabetes Complications, 20: 246-251.

28- Luo D, Zhu B, Zheng Z, Zhou H, Sun X, Xu $X$ (2014): Subtenon vs. Intravitreal triamcinolone 
injection in diabetic macular edema, A prospective study in Chinese population. Pak J Med Sci., 30:749-54.

29- El-Sayed SHa, Ellakwa AF, Badawi NMa Aml and Abd El-Razik AM (2014): Intravitreal versus subtenon injection of triamcinolone acetonide for diabetic macular edema. Menoufia Medical Journal, 27:636-642.

\section{0- El Zankalony Y, El Barbary M, Raslan O} (2012): A comparative study between intravitreal and subtenon triamcinolone acetonide in the treatment of diabetic macular edema. Am J Ophthalmol., 152:402-405.

31- Shen L, You Y, Sun S, Chen Y, Qu J (2010): Intraocular and systemic pharmacokinetics of triamcinolone acetonide after a single 40-mg posterior subtenonapplication.Ophthalmology, 11:2365-71.

32- Ibraheem RF, Iqbal W, and Rehman F (2016): Role of posterior sub-tenon triamcinolone acetonide in patients of refractory macular oedema. J Pak Med Assoc., 66: 1602-05

33- Park HJ, Lee JE, Kim SI (2014): Intravitreal pharmacokinetics after posterior subtenon triamcinolone acetonide injection in vitrectomized rabbit eyes. Retina, 34: 801-806.

34- Mueller AJ, Jian G, Banker AS, Rahhal FM, Capparelli E, Freeman WR (1998): The effect of deep posterior subtenon injection of corticosteroids on intraocular pressure. Am J Ophthalmol., 125: 158-63. 